\title{
Niveles de intensidad de instrumentos musicales
}

\author{
José Lisandro Reyes Alonzo \\ biofisica2004@yahoo.es \\ Universidad Nacional Autónoma de Honduras \\ Facultad de Ciencias \\ Escuela de Física
}

\section{Resumen}

\begin{abstract}
Al escuchar diferentes instrumentos musicales se logra apreciar que algunos son bastante sonoros y los de viento de los que se oyen más fuerte. En esta investigación se estuvo midiendo los niveles de intensidad de algunos instrumentos musicales para conocer sus niveles de intensidad utilizando un sonómetro digital. Posteriormente se estuvo midiendo el nivel de intensidad en el corredor central en el edificio donde está ubicado el Departamento de Arte y conocer que tan apropiado o no es el local para que los estudiantes de la carrera logren sus estudios. El proyecto fue realizado con la colaboración de estudiantes de la carrera de Medicina y matriculados en la clase de Biofísica. Los estudiantes realizaron una continua medición de 8:00 a 16:00 y los resultados nos muestran la necesidad de mejorar esas instalaciones que garanticen el éxito de sus estudiantes.
\end{abstract}

\section{INTRODUCCIÓN}

$\Lambda$ Ctualmente la carrera de Arte de la Universidad Nacional de Honduras ha tenido un gran desarrollo en la formación de músicos profesionales y seguirá creciendo. Las instalaciones que posee están en el cuarto piso del edificio C1 como se la ha llamado actualmente (edificio 5 anteriormente) y cuando los estudiantes desempeñan su cotidiana labor, su aprovechamiento es atenuado por los niveles de intensidad percibidos simultáneamente debido a que no existen instalaciones adecuadas en ese piso. El nivel de intensidad de algunos instrumentos de viento como el saxófono alto puede alcanzar hasta $103 \mathrm{~dB}$ de nivel de intensidad y la ejecución simultánea por largo período de muchos instrumentos logra incrementar el nivel de intensidad hasta afectar el oído de los ejecutantes. Es necesario monitorear esos niveles de intensidad que actualmente los músicos de la carrera de arte están percibiendo y ver la manera de aislarlos de un aula a otra aula.

A la mayoría de estudiantes les parece muy difícil estudiar física, posiblemente porque no logran aplicar sus teorías. En cambio en carreras como medicina, microbiología e ingeniería civil por mencionar algunas, logran un rápido aprendizaje porque aprenden haciendo. Que los alumnos apliquen sus conocimientos de física para realizar un estudio de la acústica donde está ubicado el Departamento de Arte me pareció muy alentador para los alumnos de La Carrera de Medicina que cursan la clase de Biofísica así que decidí utilizar un Sonómetro Digital (RADIO SHACK) y asigné a cada alumno a medir el nivel máximo percibido en el corredor del cuarto piso del edificio $\mathrm{C} 1$ con un horario de 8:00 a 18:00 hrs. por 7 días de labores.

\section{II. ¿QUÉ ES LO QUE EL OÍDO HUMANO PUEDE OÍR?}

Nuestro oído puede percibir diferentes tonos, timbres e intensidades que posee algún sonido, pero éste tiene limitaciones. Para el caso del tono, el rango de frecuencia audible normal está entre $20 \mathrm{~Hz}$ y $20 \mathrm{kHz}$. Para la intensidad tenemos que el mínimo de intensidad que percibimos es de 10-12 $\mathrm{W} / \mathrm{m}^{2}$ (umbral de audición) y el máximo es de $1 \mathrm{~W} / \mathrm{m}^{2}$ (umbral del dolor).

La percepción de la intensidad con la cual oímos depende de la frecuencia con la cual ha sido emitido y varía de persona a persona, con lo cual debemos considerar que si ha someti- 
do su oído continuamente a sonidos de gran intensidad y tiempos prolongados puede haber ya algún tipo de daño. Sobre el timbre se puede mencionar que depende de la forma de onda, de modo que el oído puede diferenciar qué fuente es la que ha producido el sonido.

En determinadas ocasiones hemos podido escuchar el sonido de diferentes instrumentos musicales y hemos percibido sus diferentes intensidades. En el caso de algunos instrumentos de viento, nos parece que son más intensos los tonos más agudos que los graves, en cambio en el piano se escucha más intenso los tonos graves que los agudos.

En la gráfica de la Figura 2 se muestra como la intensidad con la que escuchamos depende de la frecuencia con la que se ejecuta.

El espectro audible podemos subdividirlo en función de los tonos:

1. Tonos graves (frecuencias bajas, correspondientes a las 4 primeras octavas, esto es, desde los $16 \mathrm{~Hz}$ a los $256 \mathrm{~Hz}$ ).

2. Tonos medios (frecuencias medias, correspondientes a las octavas quinta, sexta y séptima, esto es, de $256 \mathrm{~Hz}$ a $2 \mathrm{KHz}$ ).

3. Tonos agudos (frecuencias altas, correspondientes a las tres últimas octavas, esto es, de $2 \mathrm{KHz}$ hasta poco más de $16 \mathrm{KHz}$ ).

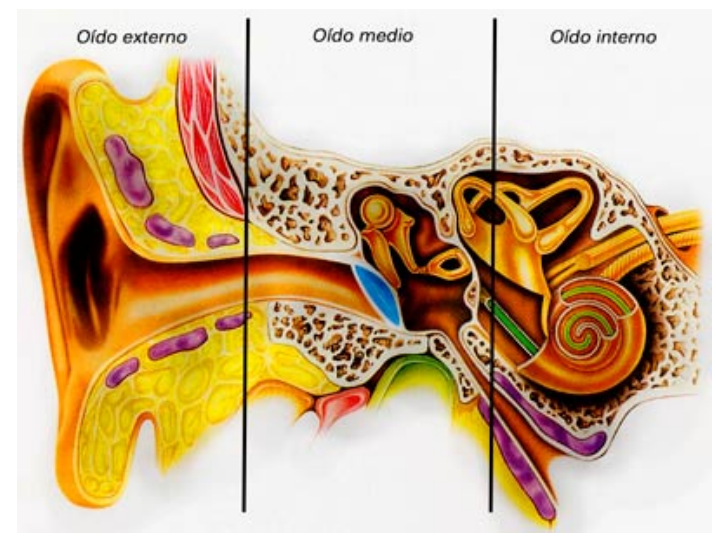

Figura 1: Oido.

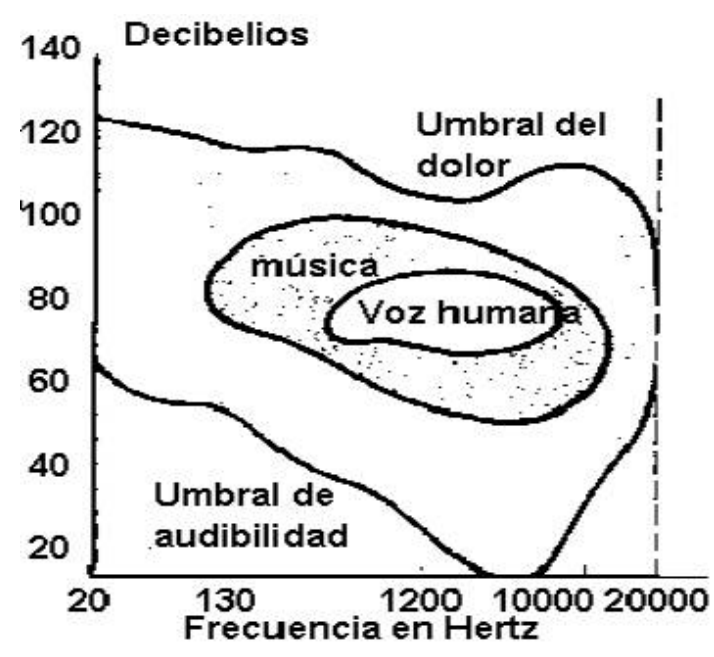

Figura 2

\section{Medición de LOS NIVELES DE INTENSIDAD}

Debido al enorme margen de intensidades audibles y a que la sensación sonora varía con la intensidad de modo no lineal, es preferible usar la escala logarítmica para describir el nivel de intensidad sonora. El nivel de intensidad b se mide en decibelios $(\mathrm{dB})$ y se define como:

$$
b=10 \log \left(\frac{I_{1}}{I_{0}}\right)
$$

Donde $I_{1}$ es la intensidad de la fuente e $I_{0}$ es la intensidad del umbral de audición.(1)

I. Frecuencias de las notas musicales

Un sonido no es más que una vibración del aire que nuestros oídos pueden captar. Un sonido que tiene un determinado tono, depende de la frecuencia a la cual vibra el aire. Las notas musicales son vibraciones de frecuencias determinadas. Por supuesto, en la creación de música intervienen muchos otros factores complejos, como por ejemplo, el timbre. En el sistema musical occidental, se ha acordado utilizar sólo unas frecuencias concretas, a las cuales llamamos notas.

Dividimos las posibles frecuencias en porciones que llamamos "octavas", y cada octava en 12 porciones que llamamos notas. Cada nota de una octava tiene exactamente la mitad 
de frecuencia que la misma nota en la octava superior. El oído humano capta solamente frecuencias que estén por encima de los $20 \mathrm{~Hz}$ y por debajo de los $20,000 \mathrm{~Hz}$ (muy aproximadamente). Así pues, y con mucha suerte, sólo podemos oír unas 10 octavas como mucho, con doce notas cada una.

La nota La sirve como referencia para todas las demás. A menudo se denomina "nota de afinar". Se produce un La de afinar cuando el aire vibra 440 veces por segundo, es decir a 440 hertzios. Por convención, a la octava que contiene esta nota La se le suele considerar la tercera.

Para hallar la frecuencia de una nota cualquiera mediante una expresión matemática, se suele coger una frecuencia de referencia, por ejemplo el La de afinar (440 Hertzios) y se multiplica por la raíz duodécima de 2 elevado al número de semitonos que separa el la de afinar de la nota que estamos buscando.

$$
f(n, o)=440(\sqrt[12]{2})^{(O-3) 12+(n+10)}
$$

donde:

n es la nota (Do es 1, Do\# es 2 y Si es 12). O es la octava (desde 1 hasta 8 ).

Usando esta ecuación se pueden obtener todas las notas musicales que logramos escuchar y que se muestran en los cuadros No. 1 y No. 2. Realizar los cálculos con una calculadora podría ser bastante entretenido, pero usando el programa de EXCEL de Microsoft es muchísimo más sencillo pues solo tiene que hacer la formula respectiva y copiarla para todas las demás notas, así como se muestra a continuación:

Cuadro 1: Hoja de EXCEL para calcular las frecuencias de notas musicales.

\begin{tabular}{lllll}
\hline & $\mathrm{A}$ & $\mathrm{B}$ & $\mathrm{C}$ & $\mathrm{D}$ \\
\hline 1 & Nota & $\mathrm{n}$ & $\mathrm{O}$ & $\mathrm{f}$ \\
2 & $\mathrm{Do}$ & 1 & 1 & $=440^{*} 2^{\wedge}(\mathrm{C} 2-3)^{*} 2^{\wedge}((\mathrm{B} 2$ \\
& & & & $-10) / 12)$ \\
3 & $\mathrm{Do}^{\#}$ & 2 & 1 & $\begin{array}{l}=440^{*} 2^{\wedge}(\mathrm{C} 3-3)^{*} 2^{\wedge}((\mathrm{B} 3 \\
\end{array}$ \\
& $\operatorname{Re}$ & 3 & 1 & $\begin{array}{l}-10) / 12) \\
=440^{*} 2^{\wedge}(\mathrm{C} 4-3)^{*} 2^{\wedge}((\mathrm{B} 4 \\
\end{array}$ \\
& & & $-10) / 12)$ \\
\hline
\end{tabular}

Es conveniente tener una idea del nivel de intensidad de algunas fuentes sonoras cotidianas. A continuación les presento algunos casos.

Cuadro 2: Nivel de intensidad de algunas fuentes sonoras cotidianas.

\begin{tabular}{lc}
\hline Fuente & $\begin{array}{c}\text { Nivel de } \\
\text { intens. (dB) }\end{array}$ \\
\hline Umbral de audición & 0 \\
Murmullo suave & 20 \\
Biblioteca & 40 \\
Hogar Promedio & 50 \\
Conversacion normal & 60 \\
Tránsito en la ciudad & 70 \\
Fábrica promedio & 80 \\
Tren Subterráneo & 90 \\
Taller de maquinaria & 100 \\
Banda Rock & 110 \\
Perforadora Neumática & 120 \\
Despegue avión a chorro & 140 \\
Lanzamiento de un & \\
cohete espacial & 180 \\
\hline
\end{tabular}

\section{Metodología de la medición}

$\mathrm{Al}$ medir los niveles de intensidad de los instrumentos se seleccionó la respuesta de medición en modo lento para obtener una medición más clara del máximo nivel. El sonómetro se colocó siempre a una distancia de medio metro en todos los casos y apoyado en un trípode para evitar ruidos del medio. Los instrumentos utilizados fueron:

- Flauta Soprano de madera Peral marca HOHNER

- Violoncelo de $3 / 4$

- Piano de la Carrera de Arte de la UNAH

- Flauta Sopranino de plástico YAMAHA

- Flauta Alto de Plástico YAMAHA

- Flauta TENOR de plástico YAMAH

- Saxofón Alto

- Clarinete

- Violín

$\mathrm{Al}$ medir el nivel de intensidad en la carrera de Arte se seleccionó un lugar en el centro de 
ese piso y se tomó mediciones tomando siempre el máximo nivel medido en intervalos de una hora desde las 8 de la mañana hasta las 6 de la tarde durante 8 días laborables (de lunes a viernes).

\section{Datos}

\section{Cuadro 3}

\begin{tabular}{lc}
\hline Instrumento & Nivel máximo \\
\hline Violoncelo de $3 / 4$ & $100 \mathrm{~dB}$ \\
Clarinete & $110 \mathrm{~dB}$ \\
Piano & $71 \mathrm{~dB}$ \\
Saxofón Contralto & $103 \mathrm{~dB}$ \\
Flauta Dulce Hohner & $91 \mathrm{~dB}$ \\
\hline
\end{tabular}

Niveles de intensidad máximos medidos en la Carrera de Arte:

\section{Cuadro 4}

\begin{tabular}{lcc}
\hline Día & Hora & Nivel(dB) \\
\hline 29 de abril & 8 a 9 & 88 \\
30 de abril & 8 a 9 & 89 \\
2 de mayo & 10 a 11 & 88 \\
3 de mayo & 8 a 9 & 81 \\
6 de mayo & 8 a 9 & 88 \\
7 de mayo & 15 a 16 & 88 \\
8 de mayo & 15 a 16 & 81 \\
14 de mayo & 14 15 & 87 \\
\hline & Promedio & 86.25 \\
\hline
\end{tabular}

\section{Análisis de la acústica}

Según los datos obtenidos se logra observar que algunos instrumentos musicales al ejecutarse logran alcanzar un nivel de intensidad hasta de 103 como el caso del saxofón alto el cual es bastante intenso para el ejecutante y si tomamos en cuenta que ellos están también percibiendo la intensidad de fondo que en promedio fue de $86.26 \mathrm{~dB}$ tendríamos un nivel total de:

$$
d B_{\text {total }}=10 \log \left(\frac{I_{1}+I_{2}}{I_{0}}\right)=103.09 \mathrm{~dB}
$$

Donde:

$I_{1}$ : Intensidad del safoxón.
$I_{2}$ : Intensidad del fondo.

Para un músico que practica con instrumentos de tan alto nivel de intensidad, el efecto de fondo casi ni lo afecta tanto pero por otro lado, el nivel de intensidad de fondo si afecta constantemente a todos los demás músicos al momento de la práctica cotidiana ya que observamos que desde las 8 de la mañana hasta las 6 de la tarde el nivel de intensidad de fondo nunca en promedio alto para realizar actividades de:

- Afinamiento de instrumentos

- Impartir clase

- Concentración al ejecutar el instrumento

\section{CONCLUSIÓN}

Para un músico que practica a diario muchas horas, estar percibiendo diariamente un nivel de intensidad como el que hemos señalado, no le permite realizar una concentración Optima. Para aislar las habitaciones del sonido existen dos formas, la más antigua es la que dice que el sonido pasa con mayor dificultad cuando el elemento que separa a la fuente del receptor es más pesado pero existen materiales menos engorrosos que se pueden usar con mucho éxito tales como por ejemplo:

- Planchas de corcho

- Aglomerados de madera

- Rellenos de lana de roca

- Fibra de vidrio

- Poliestireno

Todos esos colocados entre dos tabiques. Cuando no hay doble tabique, la solución más sencilla es aislar la habitación con planchas de yeso laminado o cartón yeso, prefabricadas, y con el correspondiente material de aislamiento adherido a una de sus caras. Únicamente perderás unos centímetros de espacio, el de la plancha y su aislante.

\section{REFERENCIAS}

[1] W. Buffa, Física General. 5 ed. 